\title{
Sistema de integração lavoura-pecuária: efeito do manejo da altura em pastagem de aveia preta e azevém anual sobre o rendimento da cultura da soja
}

\author{
Crop-livestock integration system: effect of oat and italian ryegrass sward height management on \\ soybean yield
}

\author{
Marília Lazzarotto Terra Lopes ${ }^{*}{ }^{*}$ Paulo César de Faccio Carvalho ${ }^{\mathrm{I}}$ Ibanor Anghinoni ${ }^{\mathrm{II}}$ \\ Davi Teixeira dos Santos ${ }^{\mathrm{I}}$ Angelo Antonio Queirolo Aguinaga ${ }^{\mathrm{I}}$ João Paulo Cassol Flores ${ }^{\mathrm{II}}$ \\ Anibal de Moraes ${ }^{\text {II }}$
}

RESUMO

O objetivo deste trabalho foi avaliar os efeitos da altura de manejo em pastagem de aveia preta e azevém anual sobre o estabelecimento e o rendimento de grãos da cultura de soja. Os tratamentos utilizados foram quatro alturas de manejo do pasto: 10, 20, 30 e $40 \mathrm{~cm}$ e um tratamento sem pastejo. Foram avaliados atributos referentes à pastagem (altura do pasto, oferta de forragem, massa de forragem, taxa de acúmulo, taxa de lotação animal e palhada residual) e à cultura da soja (estande inicial de plantas e rendimento de grãos). As alturas reais do pasto ficaram próximas daquelas pretendidas, havendo um aumento linear da oferta de forragem e da massa de forragem quando foi observado aumento das alturas de manejo do pasto. A taxa de acúmulo não foi afetada pelos tratamentos. A taxa de lotação apresentou resposta linear decrescente com o aumento da altura do pasto. A massa de forragem remanescente aumentou na medida em que houve incremento na altura de manejo do pasto. Foi observada diferença entre os tratamentos para palhada residual e estande inicial de plantas de soja, porém essas diferenças não afetaram o rendimento de grãos da cultura. Os resultados sugerem que a presença dos animais não prejudica o cultivo subsequente, possibilitando aumento da renda do produtor pela oportunidade de utilização das áreas durante a entressafra da soja.

Palavras-chave: intensidade de pastejo, rotação de culturas, manejo da pastagem, taxa de lotação.

\begin{abstract}
This trial aimed to evaluate the effects of sward height management of pastures composed by black oat and Italian ryegrass upon soybean establishment and yield. The treatments were four sward management heights: 10, 20, 30 and $40 \mathrm{~cm}$; and no grazing control. Pasture (sward height, herbage allowance, herbage mass, stocking rate and post grazing herbage mass) and soybean (initial stand of plants and yield) attributes were evaluated. The observed sward heights were very similar to those previously intended. There was a linear increase in herbage allowance and herbage mass with increasing sward height management. Forage accumulation rate was not influenced by treatments. Stocking rate decreased linearly with increasing sward height. Post grazing herbage mass increased with increasing sward height. Treatments had effect on initial soybean stand, but soybean yield was not affected. Results suggest grazing animals do not damage succeeding crop, allowing farmers profitability enhancement by using those areas during soybean intercropping.
\end{abstract}

Key words: grazing intensity, crop rotation, sward management, stocking rate.

\section{INTRODUÇÃO}

O Rio Grande do Sul apresenta condições edafoclimáticas bastante propícias para o desenvolvimento de atividades agrícolas e pecuárias.

\footnotetext{
IPrograma de Pós-graduação em Zootecnia, Departamento de Plantas Forrageiras e Agrometeorologia, Faculdade de Agronomia, Universidade Federal do Rio Grande do Sul (UFRGS), 90560-005, Porto Alegre, RS, Brasil. E-mail: mterralopes@hotmail.com. *Autor para correspondência.

IIPrograma de Pós-graduação em Ciência do Solo, Departamento de Solos, Faculdade de Agronomia, UFRGS, Porto Alegre, RS, Brasil.

IIIPrograma de Pós-graduação em Fitotecnia, Departamento de Fitotecnia e Fitossanitarismo, Faculdade de Agronomia, Universidade Federal do Paraná (UFPR), Curitiba, PR, Brasil.
} 
A agricultura nesse Estado vem sendo conduzida, ao longo dos anos, de forma bastante intensiva durante o verão, sendo cultivados, aproximadamente, cinco milhões de hectares com soja e milho (CONAB, 2007). No inverno, entretanto, apenas $18 \%$ desse total são cultivados com trigo, aveia, cevada e centeio, restando aproximadamente quatro milhões de hectares sem geração de renda. Nesse contexto, verifica-se a oportunidade de integração da produção de grãos, no verão, com a atividade pecuária, que poderia ser realizada nas áreas que permanecem em pousio ou naquelas apenas ocupadas por culturas de cobertura durante o inverno.

Os sistemas de integração lavoura-pecuária (SILP) possibilitam a produção de gramíneas hibernais, como aveia preta (Avena strigosa Schreb.) e azevém (Lolium multiflorum Lam.), amplamente utilizadas como culturas de cobertura de solo em áreas sob semeadura direta, para a formação de pastagens, tornando a atividade pecuária uma alternativa economicamente viável. A pecuária proporciona aumento na diversidade de atividades, permitindo maior giro de capital e gerando maior renda por unidade de área, além de possibilitar menor risco econômico às propriedades rurais.

Segundo MORAES et al. (2002), o principal entrave para a adoção dos SILP seria a possibilidade de compactação do solo provocada pelo pisoteio dos animais em pastejo. No entanto, não foram verificados efeitos do pisoteio animal sobre a densidade, a porosidade e a compressibilidade do solo em área de pastagem de aveia preta e azevém anual, sob lotação contínua em alturas de pasto variando entre 10 e $40 \mathrm{~cm}$ (CASSOL, 2003; FLORES et al., 2007). Em um Argissolo Vermelho, cultivado com aveia preta (Avena strigosa Schreb.) + trevo subterrâneo (Trifolium subterraneum Lam.) em consórcio, TREIN et al. (1991) constataram aumento na densidade e resistência à penetração, em associação com a consequente diminuição da macroporosidade e da infiltração de água, somente na camada superficial do solo $(0-7,5 \mathrm{~cm})$, após pastejo com alta intensidade e em curto espaço de tempo (200 novilhas ha-1 por 36 horas), sem terem ocorrido alterações nas camadas subsuperficiais. BOENI et al. (1995), avaliando a camada 0-10 cm de um solo francosiltoso, em área de pastagem de aveia + azevém com intensidade de pastejo moderada, não encontraram efeito do pisoteio em lotação contínua de junho a outubro. Segundo MORAES et al. (2002), os resultados de pesquisas em SILP atestam que a terminação de novilhos em sistema integrado com a produção de grãos constitui uma alternativa viável do ponto de vista de otimização do uso da terra, desde que a utilização das pastagens ocorra de forma adequada ao sistema como um todo.

Em SILP, mais importante do que a busca pela maximização da produção em cada um dos segmentos (agricultura e pecuária) é a manutenção do equilíbrio em condições ótimas para que o sistema responda de forma eficiente e torne-se sustentável a longo prazo. O desafio é encontrar um nível de biomassa de forragem que promova elevado desempenho animal, ao mesmo tempo em que se permita criar um ambiente para alcançar alto rendimento de grãos na cultura subsequente. Uma das questões centrais aos SILP é o nível crítico de biomassa que deve permanecer sobre o solo após a saída dos animais, de maneira a permitir um bom estabelecimento da cultura de verão implantada via semeadura direta.

Com respeito ao manejo e à produção animal em áreas sob SILP no Sul do Brasil, avanços recentes têm sido relatados na literatura (AGUINAGA et al., 2006; TERRA LOPES et al., 2008). No entanto, estudos referentes ao manejo dessas áreas sob pastejo e seu efeito na produção de grãos subsequente ainda são escassos. A resposta em termos de rendimento de grãos, particularmente referente à cultura da soja, é de informação escassa na literatura, quando o contexto se refere a sistemas integrados. Assim sendo, o objetivo deste trabalho foi avaliar os efeitos da altura de manejo de pastagem de aveia preta e azevém anual sobre o estabelecimento e o rendimento de grãos da cultura de soja subsequente.

\section{MATERIAL E MÉTODOS}

O experimento foi conduzido em área pertencente à Fazenda do Espinilho, localizada no Município de Tupanciretã, Rio Grande de Sul (RS), na região fisiográfica do Planalto Médio. O solo é classificado como Latossolo Vermelho Distroférrico típico (EMBRAPA, 2006), sendo profundo, bem drenado, vermelho escuro e com textura argilosa $(0,54$; 0,17 e $0,29 \mathrm{~kg} \mathrm{~kg}^{-1}$ de argila, silte e areia, respectivamente, na camada de $0,0-20,0 \mathrm{~cm})$. O relevo configura-se como ondulado a suavemente ondulado. Segundo o sistema de Köppen, o clima é do tipo Cfa, subtropical úmido. A área experimental (21,0ha) vem sendo manejada sob sistema de semeadura direta desde 1993. Anteriormente à instalação do experimento, cultivava-se aveia para produção de sementes, no inverno, e soja, no verão. No inverno do ano de 2001, com a implantação deste trabalho, a área foi utilizada pela primeira vez com animais em pastejo com o objetivo de realizar a terminação de novilhos superprecoces. O período experimental teve início em 10 de maio de 2004, com a 
semeadura de uma mistura de aveia preta $\left(100 \mathrm{~kg} \mathrm{ha}^{-1}\right.$ de sementes) mais azevém anual (25kg ha-1 de sementes), sendo utilizada como adubação de base $150 \mathrm{~kg} \mathrm{ha}^{-1}$ da fórmula 05-20-20. Aos 40 dias após a semeadura, foram aplicados, em cobertura, 66 $\mathrm{kg} \mathrm{ha}^{-1}$ de nitrogênio $(\mathrm{N})$, na forma de uréia.

Os tratamentos consistiram de quatro alturas de manejo do pasto: 10, 20, 30 e 40cm, além de um tratamento sem pastejo (SP), utilizado como testemunha. Estes foram distribuídos num delineamento experimental de blocos ao acaso, com três repetições. O monitoramento da altura do pasto foi realizado com o método da régua (sward stick), proposto por BARTHRAM (1985), em que um marcador corre por uma "régua" até tocar em alguma superfície foliar do dossel. Em cada data de avaliação, foi realizada a leitura de 100 pontos amostrais para compor o valor médio de altura de cada unidade experimental. A fim de que as alturas pretendidas fossem mantidas constantes, ajustes na taxa de lotação foram realizados em intervalos de aproximadamente 15 dias, perfazendo um total de nove avaliações.

O experimento compreendeu um período em pastejo, que teve início no dia 12 de julho de 2004, momento no qual os pastos apresentavam $23,2 \mathrm{~cm}$ de altura média e massa de forragem de aproximadamente $1.500 \mathrm{~kg} \mathrm{ha}^{-1}$ de matéria seca (MS), e também um período de avaliação da lavoura de soja subsequente, que iniciou em 14 de novembro de 2004, momento da saída dos animais.

Para manter constantes as alturas pretendidas, utilizou-se, além dos três animais-teste, um número variável de animais reguladores, aplicandose a técnica de lotação contínua com taxa de lotação variável descrita por MOTT \& LUCAS (1952). Foram utilizados novilhos com idade inicial média de 10 meses, castrados, oriundos de cruzamento de Angus, Hereford e Nelore, com peso vivo médio inicial de $190 \mathrm{~kg}$ e de abate de $318 \mathrm{~kg}$. A taxa de lotação (TL) do período de pastejo, expressa em $\mathrm{kg} \mathrm{ha}^{-1}$ de peso vivo (PV), foi calculada pela adição do peso médio dos animais-teste com o peso médio de cada animal regulador, multiplicado pelo número de dias que estes permaneceram na pastagem, dividido pelo número total de dias de pastejo. Nos pastos, foram avaliadas a massa de forragem (MF, $\mathrm{kg} \mathrm{ha}^{-1}$ de MS), a taxa de acúmulo diário (TAC, $\mathrm{kg} \mathrm{ha}^{-1}$ de MS) e a produção total de forragem (PMS, $\mathrm{kg} \mathrm{ha}^{-1}$ de MS). Para a estimativa da MF, foi utilizada a técnica de dupla amostragem (WILM et al., 1944). A TAC foi monitorada a cada 30 dias utilizando-se três gaiolas de exclusão ao pastejo por unidade experimental, empregando a técnica do triplo emparelhamento descrita em MORAES et al. (1990). A
MF dentro e fora da gaiola foi obtida pela média dos cortes avaliados. Todos os cortes foram feitos rente ao solo, em área de $0,25 \mathrm{~m}^{2}$. As amostras foram pré-secadas em estufa de circulação forçada a $65^{\circ} \mathrm{C}$, até peso constante. A produção total de MS foi estimada pelo somatório das produções dos sub-períodos (taxa de acúmulo x número de dias do sub-período), somada à massa de forragem no início do pastejo. A oferta de forragem foi obtida pela razão entre a produção total de MS e a taxa de lotação animal média do período experimental em pastejo.

A avaliação da cultura de verão teve início após a saída dos animais, em 18 de novembro de 2004, quando foi realizada a aplicação de herbicida de ingrediente ativo (i.a.) Glyphosate, na dosagem de 2,5L ha $^{-1}$ do produto comercial (p.c.). Já em 05 de dezembro de 2004 foi semeada a cultivar de soja 'Iguaçu', inoculada com inoculante específico. Foram utilizadas 14 sementes por metro linear, num espaçamento de $45 \mathrm{~cm}$ entre linhas, objetivando a densidade de 350.000 sementes ha ${ }^{-1}$. Nesse momento, fez-se uma adubação de base, sendo utilizados $300 \mathrm{~kg} \mathrm{ha}^{-1}$ de superfosfato simples. A cultura da soja foi implantada no sistema de semeadura direta utilizando-se uma semeadoraadubadora PSM HY-TECH 8000 SFIL, com oito linhas e $2.800 \mathrm{~kg}$ de peso, equipada com disco liso (17”), um sulcador de adubo do tipo facão e um sulcador de sementes do tipo discos duplos desencontrados. A velocidade de semeadura foi de $5,5 \mathrm{~km} \mathrm{~h}^{-1}$.

Para verificar o efeito das alturas de manejo do pasto sobre o estabelecimento da cultura da soja, avaliou-se o estande de plantas (EP) de soja aos 30 dias após a emergência. Essa avaliação foi feita pela contagem do número de plantas contidas em um metro linear, repetindo-se esse procedimento em 10 pontos amostrais em cada unidade experimental (UE). As avaliações do rendimento de grãos foram realizadas no estádio de maturação fisiológica. Para essa avaliação, foram amostradas as plantas contidas em um metro linear, repetindo-se esse procedimento em 10 pontos aleatórios por UE. Os grãos de soja, após passarem por debulha manual, foram pesados e tiveram os seus teores de umidade mensurados. O cálculo do rendimento de grãos por hectare foi ajustado para o teor de umidade de $13 \%$.

Os dados foram submetidos à análise de variância, ao teste $\mathrm{F}$ e à regressão ao nível de 5\%, pelo aplicativo computacional SAS (1997). Para as análises de regressão, foram estimadas as variáveis-resposta segundo valores de alturas reais do pasto. Sempre que a função-resposta foi significativa $(\mathrm{P}<0,05)$, optou-se por apresentar os resultados pela equação de regressão de maior coeficiente de determinação $\left(\mathrm{R}^{2}\right)$. 


\section{RESULTADOS E DISCUSSÃO}

Os valores das alturas observadas nos pastos ficaram próximos dos valores pretendidos, com diferença entre os tratamentos $(\mathrm{P}<0,05)$, um requisito essencial para configurarem-se os contrastes propostos. Os valores reais foram 12, 19, 28, 32 e 40cm para os tratamentos $10,20,30$ e $40 \mathrm{~cm}$ e $\mathrm{SP}$, respectivamente. Houve aumento linear $(\mathrm{P}<0,05)$ da oferta de forragem quando foi observado aumento da altura de manejo dos pastos (Figura 1). A massa de forragem também teve resposta linear e positiva $(\mathrm{P}<0,05)$ ao aumento das alturas de manejo. Já a taxa de lotação (Figura 2) apresentou resposta linear decrescente $(\mathrm{P}<0,05)$ com o aumento da altura dos pastos. De acordo com o modelo gerado, cada $\mathrm{cm}$ de incremento na altura do pasto corresponde a uma redução de, aproximadamente, $46 \mathrm{~kg} \mathrm{ha}^{-1} \mathrm{de}$ PV na taxa de lotação.

O aumento da MF pode ser atribuído à maior oferta de forragem e, consequentemente, à menor taxa de lotação nesses tratamentos, tal como em PONTES et al. (2003). Na avaliação da MF, cada centímetro de incremento na altura do pasto representou um acréscimo de $119 \mathrm{~kg} \mathrm{ha}^{-1}$ de MS, expresso pela equação $y=224,11+118,68 x\left(R^{2}=0,997\right)$ (Figura 1). Esses valores são semelhantes aos obtidos por CASSOL (2003), que encontrou coeficientes de regressão de 130 e $133 \mathrm{~kg}$ $\mathrm{ha}^{-1}$ de MS para o mesmo tipo de pastagem, em dois anos consecutivos. Tanto os resultados obtidos no presente estudo, quanto aqueles encontrados por
CASSOL (2003), corroboram a possibilidade de predizer a massa de forragem por meio da mensuração da altura do pasto. Esta pode ser utilizada, então, como determinante de metas de condição da pastagem conforme o objetivo que se deseja alcançar nos SILP. Já a taxa de acúmulo de MS não foi afetada pela altura de manejo dos pastos ( $\mathrm{P}>0,05)$, sendo o valor médio encontrado de $50,3 \mathrm{~kg} \mathrm{ha}^{-1} \mathrm{dia}^{-1}$ de MS. Isso evidencia possíveis limitações da metodologia utilizada, pois esta poderia estar favorecendo o acúmulo de forragem nas menores alturas de pasto e subestimando nas maiores, diminuindo a amplitude de eventuais diferenças entre pastagens baixas e altas (FRAME, 1981).

O manejo da massa de forragem tem grande importância, sobretudo porque pode determinar o sucesso ou fracasso dos SILP. Em tese, a manutenção de baixa biomassa residual pode vir a comprometer o sistema em semeadura direta, uma vez que quantidades pequenas de massa ou menores alturas de manejo ocasionariam degradação e prejuízos do ponto de vista físico do solo.

A palhada residual (Figura 3) aumentou de forma linear positiva ao aumento da altura do pasto $(\mathrm{P}<0,05)$. Os valores encontrados variaram de $1.860 \mathrm{a}$ $5.170 \mathrm{~kg} \mathrm{ha}^{-1}$ de MS, da menor para a maior altura, respectivamente. A sua presença na superfície do solo pode funcionar como uma barreira amortecedora ao pisoteio animal. Tal efeito foi observado por BASSANI (1996) e SILVA et al. (2000), que não encontraram efeito do pisoteio animal sobre os atributos físicos do solo, o que foi atribuído à massa de forragem média de aveia e

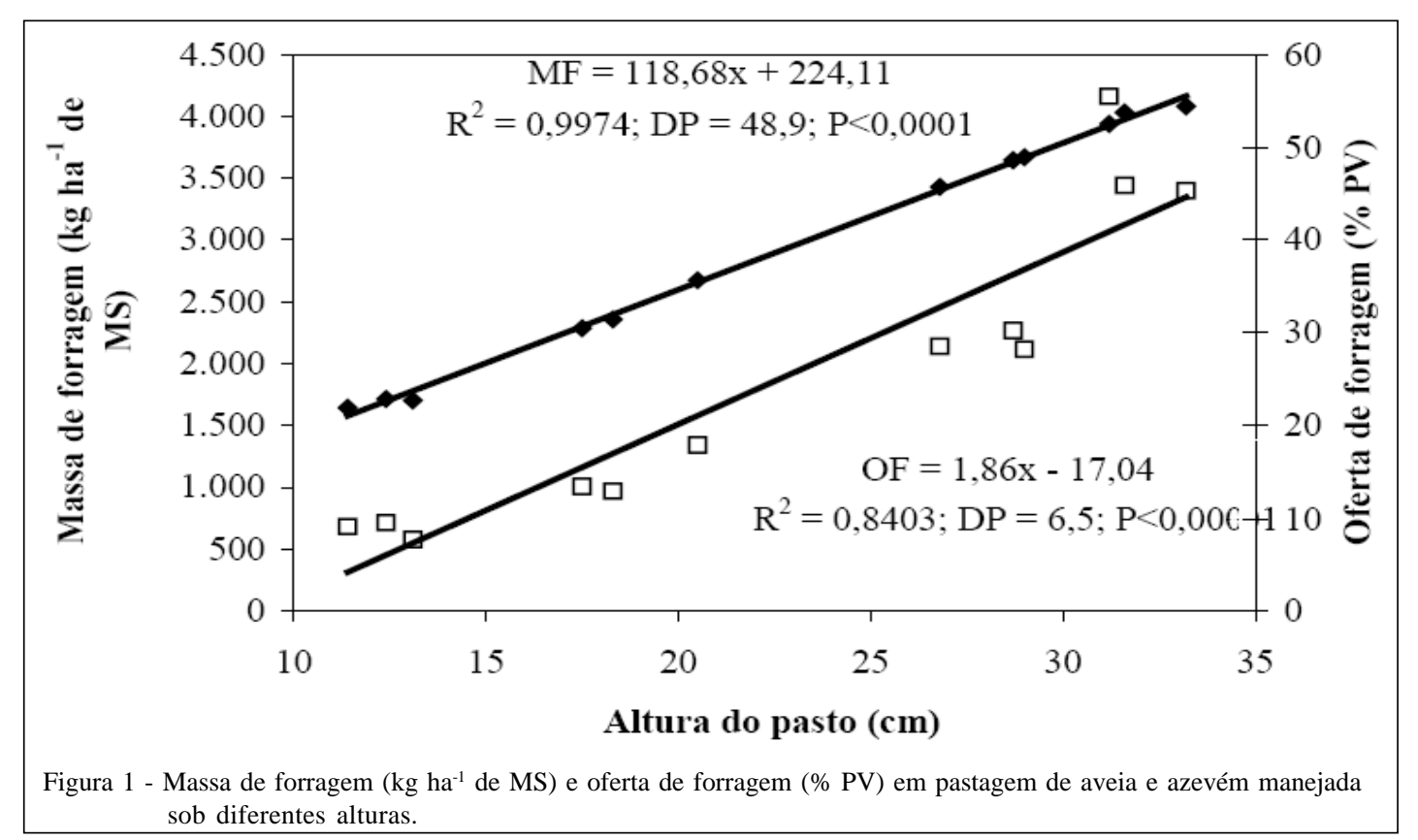

Ciência Rural, v.39, n.5, ago, 2009. 


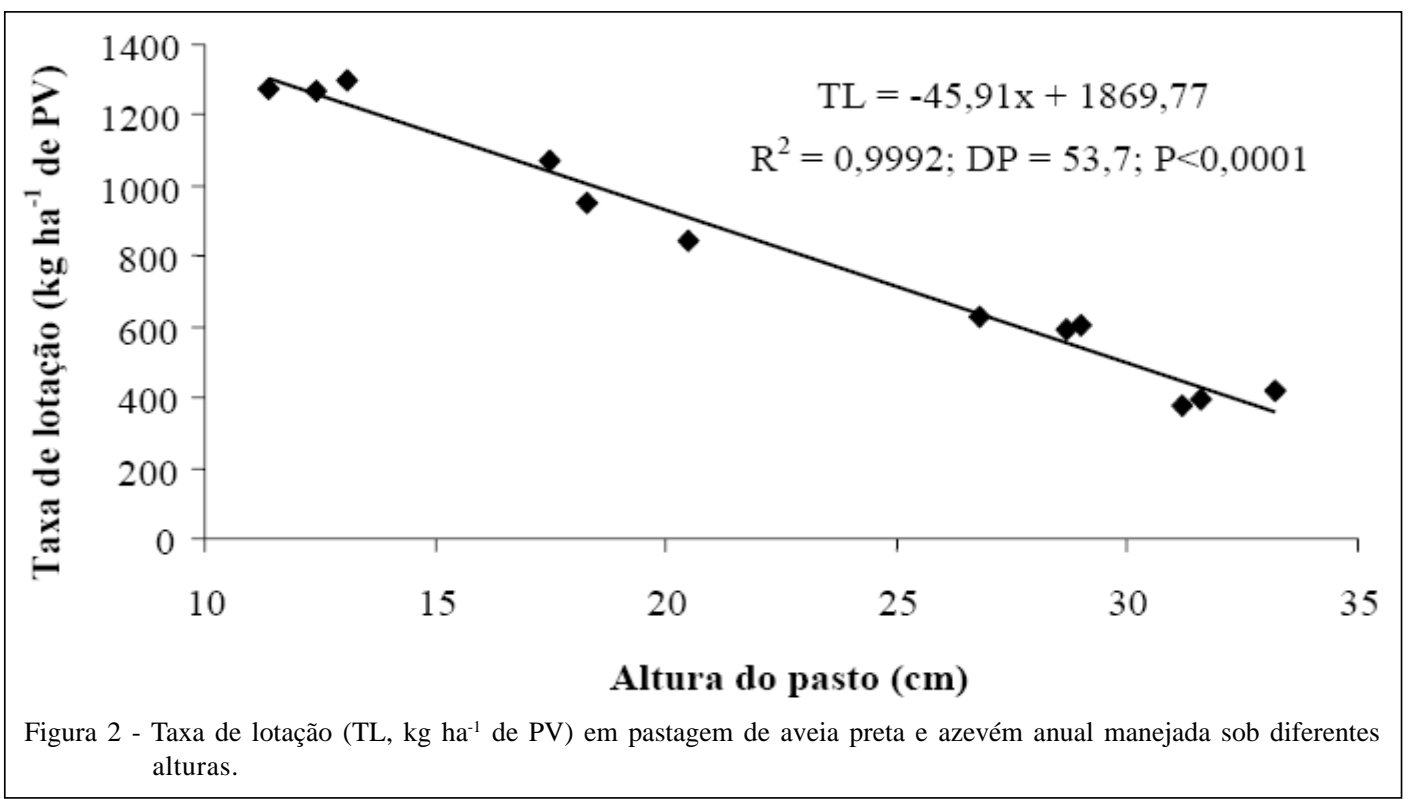

azevém mantida durante todos os períodos de pastejo (2.000 e 1.000 $\mathrm{kg} \mathrm{ha}^{-1}$ de MS, respectivamente). FLORES et al. (2007), trabalhando sob as mesmas condições experimentais do presente estudo, obtiveram quantidades de palhada na superfície do solo variando de 1.850 a $5.400 \mathrm{~kg} \mathrm{ha}^{-1}$ de MS, da maior para a menor intensidade de pastejo, respectivamente, sendo observados $6.050 \mathrm{~kg} \mathrm{ha}^{-1}$ de MS na área sem pastejo. Nessas condições, não houve diferenças nos atributos físicos do solo relacionados com a compactação, e os autores observaram que, mesmo com níveis de palhada residual próximos a $2.000 \mathrm{~kg} \mathrm{ha}^{-1}$ de MS, não houve comprometimento da produção de grãos de soja no cultivo subsequente.

A adição de resíduos vegetais ao solo em áreas sob SILP, em semeadura direta, é de extrema importância para a manutenção e o aumento dos teores de matéria orgânica do solo (MOS), a qual tem um papel fundamental na manutenção da sustentabilidade da produção ao longo do tempo. Nas condições climáticas do RS, a adição anual de palha ao solo, no sistema de plantio direto, deve ser superior a $8.000 \mathrm{~kg} \mathrm{ha}^{-1}$ de MS de resíduos vegetais (NICOLOSO et al., 2006; LOVATO et al., 2004) para que sejam mantidos estáveis os teores de MOS.

Na figura 3, também se encontram os resultados relacionados ao estande de plantas (EP) da lavoura de soja durante o verão subsequente à utilização da pastagem de aveia e azevém. Observa-se que as alturas de manejo do pasto influenciaram, de forma linear $(\mathrm{P}<0,05)$, o EP aos 30 dias após a emergência. Os menores valores observados de EP, nos tratamentos de menor altura de manejo do pasto, podem ter sido ocasionados pelo comprometimento da semeadura, ficando as sementes na superfície, em condições inadequadas para a germinação (TREIN et al., 1991). Contribuiria para isso o fato de que, no momento do plantio, as áreas submetidas às maiores intensidades de pastejo possam ter provocado um maior esforço de tração na semeadora. Tal situação foi observada por CONTE et al. (2007), cujos registros do esforço de tração em hastes sulcadoras de adubo variaram entre 2665 e $3610 \mathrm{kPa}$ na profundidade de $0-12 \mathrm{~cm}$, respectivamente da menor para a maior intensidade de pastejo (mesmo protocolo experimental deste trabalho). Além disso, a umidade do solo no momento do plantio foi menor nos tratamentos de menor altura de manejo, fruto da menor massa residual deixada pelos animais. Nesse sentido, a diferença em umidade gravimétrica no momento do plantio é pronunciada, registrando-se valores de $0,19 \mathrm{~kg}$ $\mathrm{kg}^{-1}$ para as maiores alturas de manejo e de $0,12 \mathrm{~kg} \mathrm{~kg}^{-1}$ no tratamento de altura de $10 \mathrm{~cm}$ (CONTE et al., 2007). A menor cobertura nos tratamentos de menor altura de manejo não somente acarreta uma umidade menor, mas também permite uma maior infestação por plantas indesejáveis. Todos esses fatores detectados na saída dos animais e no estabelecimento da cultura da soja justificam o menor estande de plantas decorrentes desse cenário desfavorável ao estabelecimento da cultura.

Apesar das diferenças no estande de plantas, isso não se refletiu $(\mathrm{P}>0,05)$ no rendimento de grãos de soja (Figura 4), mesmo a população, no tratamento SP, sendo $36 \%$ superior à do tratamento de 


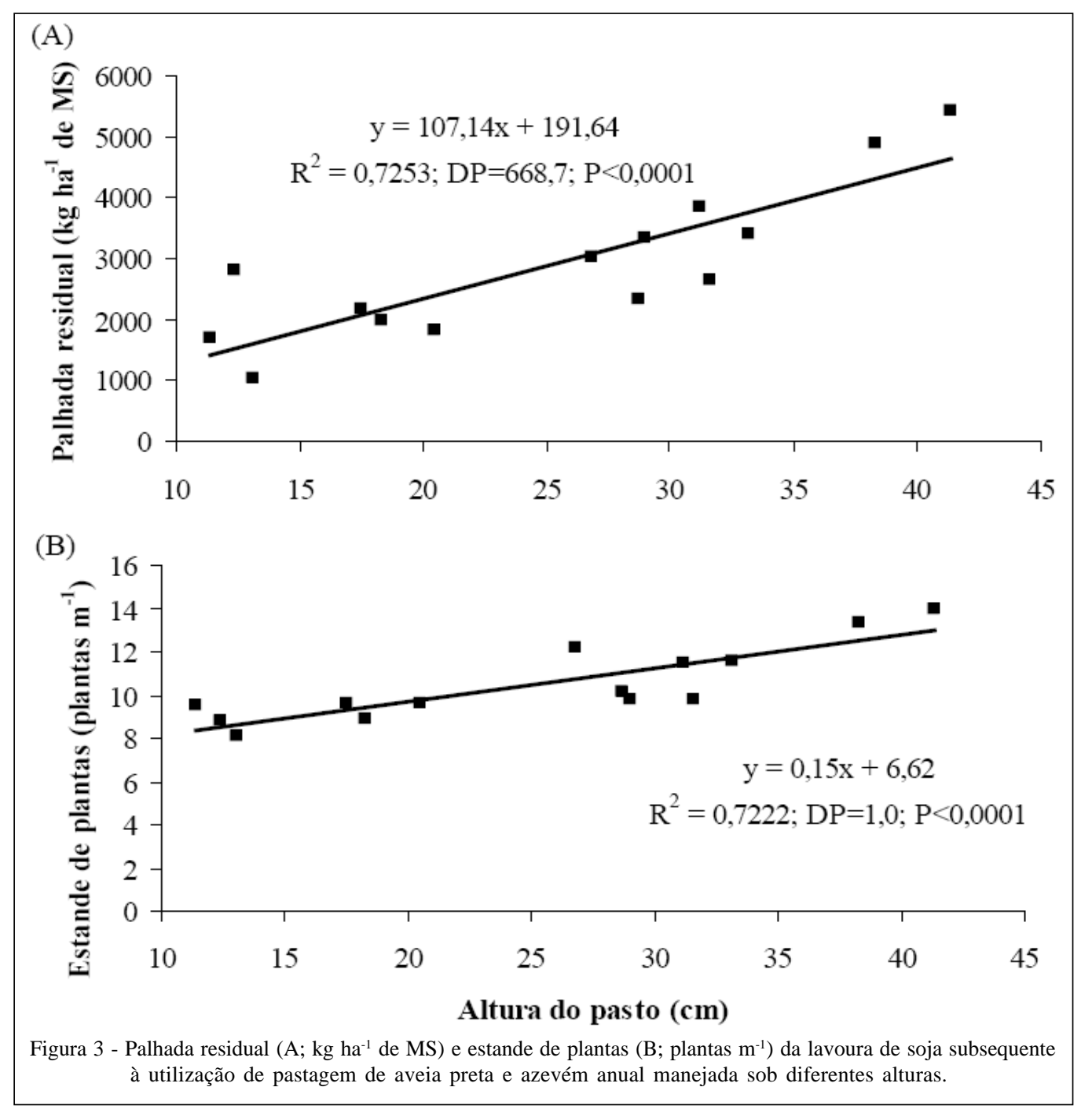

$10 \mathrm{~cm}$. Isso porque os rendimentos médios foram baixos em virtude da ocorrência de déficit hídrico, registrandose, para os tratamentos $10,20,30$ e $40 \mathrm{~cm}$ e SP, os rendimentos de 1.290, 1.300, 1.195, 1.305 e $1.025 \mathrm{~kg} \mathrm{ha}^{-1}$, respectivamente. Durante essa safra, a região sofreu um déficit hídrico de 262mm em relação à média normal de 40 anos (FEPAGRO - Estação meteorológica de Júlio de Castilhos/RS), considerando o período compreendido entre os meses de fevereiro de 2004 a janeiro de 2005. Em condições favoráveis de precipitação, não houve, no mesmo experimento, diferenças entre as alturas de manejo, tanto no estande, quanto no rendimento de soja, que variou de 3.590 a $4.050 \mathrm{~kg} \mathrm{ha}^{-1}$, para alturas de manejo de $20 \mathrm{~cm}$ e para a área sem pastejo, respectivamente, (FLORES et al., 2007).

Esse tipo de resultado é raro em milho, mas não em soja (EGLI, 1993), pois esta tem como característica peculiar a sua alta capacidade de expressar plasticidade fenotípica (ANDRADE \& ABBATE, 2005). Segundo VEGA et al. (2000), a soja é mais eficiente em apresentar índices estáveis de colheita a despeito de estandes desuniformes. As explicações para essas respostas estão associadas a mudanças nos padrões de alocação de carbono na planta. De acordo com ANDRADE \& ABBATE (2005), a soja compensa variações em seu estande de duas formas principais: primeiro, a soja tem rápida e grande capacidade de ramificação lateral, permitindo atingir índices de área foliar teto antes do momento crítico de determinação da produção da cultura; segundo, a relação entre produção por planta e acúmulo de biomassa na fase vegetativa é caracterizada por um modelo quadrático em milho, mas linear em soja. Isso resulta do ajuste que a planta faz entre o número de grãos e seu peso, que, por sua vez, reflete a quantidade de recursos tróficos 


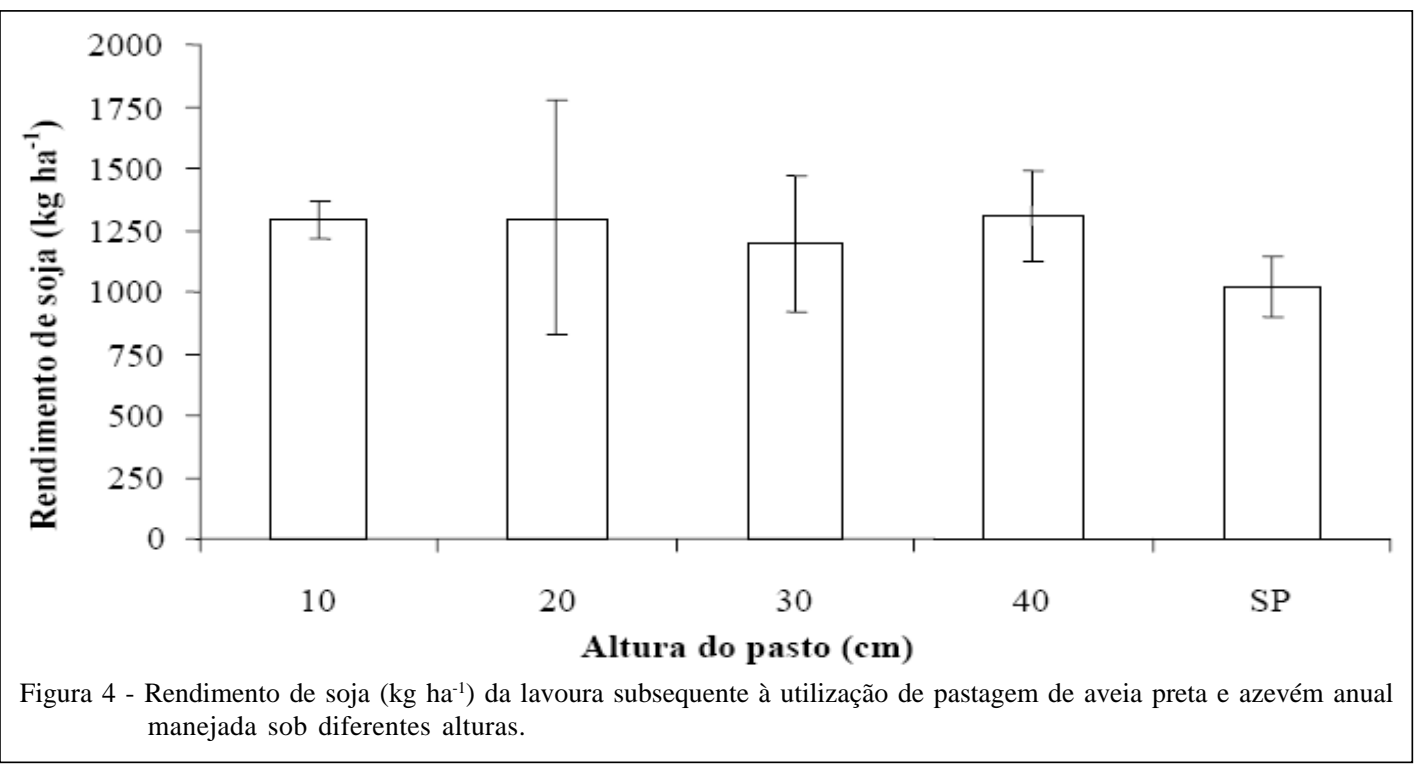

disponíveis por planta, em que a soja, aparentemente, não apresenta limites para realização de tal compensação (ANDRADE \& ABBATE, 2005).

Quando a taxa de lotação está adequada, as alterações nos atributos físicos do solo são pequenas e não causam dano à cultura em sucessão ao pastejo, em safras sem a ocorrência de períodos de estiagem (SILVA et al., 2000; ALBUQUERQUE et al., 2001; CASSOL, 2003). No presente trabalho, uma constatação relevante foi de que, mesmo em situação de déficit hídrico, a altura do pasto não foi determinante do rendimento de grãos de soja. Há resultados semelhantes, como os de LUNARDI et al. (2008), em que os autores, em situação de déficit hídrico, observaram rendimentos de 1.380 e $980 \mathrm{~kg} \mathrm{ha}^{-1}$ de soja para áreas pastejadas e sem pastejo, respectivamente.

Os resultados do presente trabalho, apesar de registrarem efeitos numa única sucessão pastagem/ cultura, foram obtidos na quarta sequência sucessiva dessa rotação, em que os tratamentos têm sido mantidos nas mesmas parcelas e conduzidos de forma análoga ao longo dos anos. Portanto, eles indicam que a produção de soja não é penalizada pela presença dos animais no ciclo precedente, mesmo em condição de resíduo de $10 \mathrm{~cm}$.

\section{CONCLUSÕES}

O estabelecimento da cultura de soja é negativamente afetado com o decréscimo da palhada residual que se transfere ao ciclo da lavoura, oriunda das diferentes intensidades de pastejo empregadas no ciclo da pastagem antecedente.
A despeito das variações no estande de plantas conforme o nível de palhada residual, o rendimento de grãos da cultura da soja subsequente não é influenciado pelo manejo da pastagem. Consequentemente, a decisão pela maior ou menor utilização da pastagem em termos de taxa de lotação dependerá, primeiramente, dos objetivos de produção (e.g. recria, terminação).

\section{REFERÊNCIAS}

AGUINAGA, A.A.Q. et al. Produção de novilhos superprecoces em pastagem de aveia e azevém submetida a diferentes alturas de manejo. Revista Brasileira de Zootecnia, v.35, n.4, p.1765-1773, 2006. Doi: 10.1590/S1516-35982006000600026.

ALBUQUERQUE, J.A. et al. Efeitos da integração lavourapecuária nas propriedades físicas do solo e características da cultura do milho. Revista Brasileira de Ciência do Solo, v.25, p.717-723, 2001.

ANDRADE, F.H.; ABBATE, P.E. Response of maize and soybean to variability in stand uniformity. Agronomy Journal, v.97, p.1263-1269, 2005.

BARTHRAM, G.T. Experimental techniques: the HFRO sward stick. In: BIENNIAL REPORT, 1985, Penicuik. Proceedings.. Penicuik: Hill Farming Research Organization, 1985. p.29-30.

BASSANI, H.J. Propriedades físicas induzidas pelo plantio direto e convencional em área pastejada e não-pastejada. 1996. 90f. Dissertação (Mestrado em Ciência do solo), Santa Maria, Universidade Federal de Santa Maria.

BOENI, M. et al. Efeito do pisoteio animal durante o pastejo de inverno sobre algumas propriedades físicas do solo. In: CONGRESSO BRASILEIRO DE CIÊNCIA DO SOLO, 25., 1995, Viçosa (MG). Anais... Viçosa (MG): Sociedade Brasileira de Ciência do Solo, 1995. V.1, p.160-161. 
CASSOL, L.C. Relações solo-planta-animal num sistema de integração lavoura-pecuária em semeadura direta com calcário na superfície. 2003. 143f. Tese (Doutorado em Ciência do Solo), Porto Alegre, Universidade Federal do Rio Grande do Sul.

CONAB. Sétimo Levantamento da avaliação da safra de grãos 2006/2007. Acesso em: 2 mai. 2007. On line. Disponível em: http://www.conab.gov.br.

CONTE, O. et al. Demanda de tração em haste sulcadora na integração lavoura-pecuária com diferentes pressões de pastejo e sua relação com o estado de compactação do solo. Engenharia Agrícola, v.27, n.1, p.220-228, 2007. Disponível em: <http:/ /www.scielo.br/scielo.php?script=sci_arttext\&pid=S0100$69162007000100016 \& \operatorname{lng}=$ en $\& n r m=$ iso\&tlng $=p t>$. Doi: 10.1590/S0100-69162007000100016.

EGLI, D.B. Relationship of uniformity of soybean seedling emergence to yield. Journal of Seed Technology, v.17, p.2228, 1993.

EMBRAPA - Centro Nacional de Pesquisas de Solos. Sistema brasileiro de classificação de Solos. 2.ed. Rio de Janeiro: EMBRAPA Solos, 2006. 306p.

FLORES, J.P.C. et al. Atributos físicos do solo e rendimento de soja em sistema plantio direto em integração lavoura-pecuária com diferentes pressões de pastejo. Revista Brasileira de Ciência do Solo, v.31, n.4, p.771-780, 2007. Disponívem em: $<$ ht tp://www.scielo.br/scielo.php? pid=S 0100 06832007000400017\&script=sci_arttext\&tlng=e>. Doi: 10.1590/ S0100-06832007000400017.

FRAME, J. Herbage mass. In: HODGSON, J. et al. (Ed.). Sward measurement handbook. Hurley, UK.: British Grassland Society, 1981. p.39-67.

LUNARDI, R. et al. Rendimento de soja em sistema de integração lavoura-pecuária: Efeito de métodos e intensidades de pastejo. Ciência Rural, v.38, n.3, p.795-801, 2008. Disponível em: $<$ http://www.scielo.br/scielo.php?pid=S 0103 84782008000300032\&script $=$ sci_arttext\&tlng $=\mathrm{e}>$. Doi: 10.1590/ S0103-84782008000300032.

LOVATO, T. et al. Adição de carbono e nitrogênio e sua relação com os estoques no solo e o rendimento do milho em sistemas de manejo. Revista Brasileira de Ciência do Solo, v.28, p.175187, 2004. Disponível em: <http://www.scielo.br/ scielo.php?pid=S0100-06832004000100017\&script=sci_arttext $>$. Doi: 10.1590/S0100-06832004000100017.

MORAES, A. et al. Comparação de métodos de taxas de crescimento em uma pastagem submetida a diferentes pressões de pastejo. In: REUNIÃO ANUAL DA SOCIEDADE BRASILEIRA DE ZOOTECNIA, 27.; 1990, Campinas. Anais... Campinas: SBZ, 1990. p.332. Disponível em: www.scielo.br/ scielo.php?pid=S1516-35982001000300004\&script=sci_arttext - 54k -.
MORAES, A. et al. Integração lavoura-pecuária no Sul do Brasil. In: ENCONTRO DE INTEGRAÇÃO LAVOURAPECUÁRIA NO SUL DO BRASIL, 2002, Pato Branco. Anais... Pato Branco: Imprepel, 2002. p.3-42.

MOTT, G.O.; LUCAS H.L. The design, conduct, and interpretation of grazing trials on cultivated and improved pastures. In: INTERNATIONAL GRASSLAND CONGRESS, 6., 1952, Pensylvania. Proceedings... Pensylvania: State College, 1952. p.1380-1385.

NICOLOSO, R.S. et al. Manejo das pastagens de inverno e potencial produtivo de sistemas de integração lavoura-pecuária no Estado do Rio Grande do Sul. Ciência Rural, v.36, n.6, p 1799-1805, 2006. Disponível em: <http://www.scielo.br/ scielo.php? script = sci_art text \& pid=S 0103 $84782006000600019 \& \operatorname{lng}=\mathrm{en} \& \mathrm{nrm}=\mathrm{iso} \& \operatorname{lng}=\mathrm{pt}>$. Doi: 10.1590/S0103-84782006000600019.

PONTES, L.S. et al. Variáveis morfogênicas e estruturais de azevém anual (Lolium multiflorum Lam.) manejado em diferentes alturas. Revista Brasileira de Zootecnia, v.32, n.4, p.814-820, 2003. Disponível em: <http://www.scielo.br/scielo.php?pid=S151635982003000400005\&script=sci_arttext $>$. Doi: 10.1590/S151635982003000400005 .

SAS INSTITUTE. User's guide statistics. 4.ed. Cary, NC, 1997. V.2, 943p. Disponível em: www.scielo.br/ scielo.php? script=sci_arttext\&pid=S010384782006000200035\&lng=e\&nr... - 55k.

SILVA, V.R. et al. Densidade do solo, atributos químicos e sistema radicular do milho afetados pelo pastejo e manejo do solo. Revista Brasileira de Ciência do Solo, v.24, p.191199, 2000.

TERRA LOPES, M.L. et al. Sistema de integração lavoura-pecuária: desempenho e qualidade da carcaça de novilhos superprecoces terminados em pastagem de aveia e azevém manejada sob diferentes alturas. Ciência Rural, v.38, n. 1, p.178-184, 2008. Disponível em: <http://www.scielo.br/scielo.php?script=sci_arttext\&pid=S0103$\begin{array}{lllllllllllllllllllll}8 & 4 & 7 & 8 & 2 & 0 & 0 & 8 & 0 & 0 & 0 & 1 & 0 & 0 & 0 & 2 & 9 & \& & 1 & n & g\end{array}$ =entarget=_blank\&nrm=iso\&tlng=entarget $=$ bblank. Doi: $10.1590 /$ S0103-84782008000100029.

TREIN, C.R. et al. Métodos de preparo do solo na cultura do milho e ressemeadura do trevo, na rotação aveia + trevo/milho após pastejo intenso. Revista Brasileira de Ciência do Solo, Campinas, v.15, n.1, p.105-111, 1991.

VEGA, C.R. et al. Reproductive allometry in soybean, maize and sunflower. Annals of Botany, v.85, pg.461-468, 2000.

WILM, H.G. et al. Estimating forage yield by the double sampling methods. Journal of American Society of Agronomy, v.36, p.194-203, 1944. 